University of Nebraska - Lincoln

DigitalCommons@University of Nebraska - Lincoln

Good vibrations? Structure and function of the cloacal tip of male Australian Maluridae

\author{
Melissah Rowe \\ University of Chicago, melissah@uchicago.edu \\ Murray R. Bakst \\ USDA \\ Stephen Pruett-Jones \\ University of Chicago
}

Follow this and additional works at: https://digitalcommons.unl.edu/usdaarsfacpub

Part of the Agricultural Science Commons

Rowe, Melissah; Bakst, Murray R.; and Pruett-Jones, Stephen, "Good vibrations? Structure and function of the cloacal tip of male Australian Maluridae" (2008). Publications from USDA-ARS / UNL Faculty. 626. https://digitalcommons.unl.edu/usdaarsfacpub/626

This Article is brought to you for free and open access by the U.S. Department of Agriculture: Agricultural Research Service, Lincoln, Nebraska at DigitalCommons@University of Nebraska - Lincoln. It has been accepted for inclusion in Publications from USDA-ARS / UNL Faculty by an authorized administrator of DigitalCommons@University of Nebraska - Lincoln. 


\title{
Good vibrations? Structure and function of the cloacal tip of male Australian Maluridae
}

\author{
Melissah Rowe, Murray R. Bakst and Stephen Pruett-Jones \\ M. Rowe (correspondence) and S. Pruett-Jones, Department of Ecology and Evolution, University of Chicago, 1101 East 57th Street, Chicago, \\ Illinois 60637, USA. Email: melissah@uchicago.edu. - M. R. Bakst, Animal Biosciences and Biotechnology Laboratory, Animal and Natural \\ Resources Institute, Agricultural Research Service, USDA, Building 200, BARC East, Powder Mill Road, Beltsville, Maryland 20705, USA.
}

\begin{abstract}
When females mate multiply, sperm competition can generate strong selection for traits that provide males with a fertilisation advantage. This study examined the cloacal tip, a unique morphological structure of males that appears to be associated with sperm competition in Australian Maluridae. Species in this group appear to experience a range of sperm competition intensities and exhibit a diversity of associated reproductive adaptations and behaviours. A prominent cloacal tip was present in the striated grasswren Amytornis striatus striatus, and superb Malurus cyaneus cyanochlamys, splendid $M$. splendens melanotus, red-backed M. melanocephalus and white-winged fairy-wrens M. leucopterus leuconotus, while variegated $M$. lamberti assimilis and blue-breasted $M$. pulcherrimus fairy-wrens possessed a rudimentary tip, and the southern emu-wren Stipiturus malachurus malachurus lacked a tip. The tip was a muscular hydrostatic appendage of the cloacal protuberance comprised of longitudinal striated muscle, a two-dimensional matrix of connective tissue and a keratinised epithelium. After controlling for phylogenetic relationships, cloacal tip length was positively related to combined testes mass but not body mass. Therefore, species inferred to experience more intense sperm competition exhibited a longer cloacal tip. We discuss the potential function of the cloacal tip and suggest that it may increase a male's likelihood of paternity success and represents a novel adaptation to sperm competition.
\end{abstract}

In many species, females mate with multiple males during a single reproductive episode. Consequently, sperm from a number of males may compete to fertilise the female's ova (Parker 1970). Intense sperm competition results in strong selection for traits that provide males with a reproductive advantage. In birds, numerous traits influence mate attraction and fertilisation success, including colourful plumage, large testes, and strategic sperm allocation (Møller 1988, 1991, Birkhead and Møller 1992, Nicholls et al. 2001). Nakamura (1990) predicted that species may also evolve special features of both reproductive behaviour and external or accessory sex organs under conditions of intense sperm competition. Here, we examine the structure and function of the cloacal tip, a unique morphological feature of male reproductive anatomy in species from the avian family Maluridae that is likely related to differences in the intensity of sexual selection.

The Maluridae are small (c. 5-40 g) insectivorous passerines distributed throughout Australia and New Guinea (Rowley and Russell 1997). In Australia, they include grasswrens Amytornis, emu-wrens Stipiturus, and fairy-wrens Malurus (Rowley and Russell 1997). Australian malurids are non-migratory, reside on stable year-round territories, and exhibit relatively similar patterns of social organisation and life history. All species are known or believed to be socially monogamous, with males and females forming multi-year pair bonds, and exhibit varying levels of cooperative breeding (Rowley and Russell 1997, Maguire and Mulder 2004).

Across birds as a whole, relative testes mass is correlated with levels of extra-pair paternity (Møller and Briskie 1995) and is commonly used as an indicator of sperm competition intensity (Dunn et al. 2001, Pitcher et al. 2005). Based on male reproductive anatomy, the Australian Maluridae appear to exhibit a range of sperm competition intensities, from low in emu-wrens, low to intermediate in grasswrens, to intense in some fairy-wren species (Rowe and PruettJones 2006). The fairy-wrens exhibit some of the highest recorded levels of extra-pair paternity in an avian species, with up to $95 \%$ of all broods containing extra-pair young (Mulder et al. 1994, Karubian 2002, Webster et al. 2004). Extra-pair paternity constitutes a significant component of reproductive success for male fairy-wrens (Webster et al. 2007) and, not surprisingly, males exhibit several adaptations associated with intense sperm competition, including relatively large cloacal protuberances (the site of sperm storage) and ritualised extra-pair courtship displays (Tuttle et al. 1996, Mulder 1997, Tuttle and Pruett-Jones 2004).

In the superb fairy-wren $M$. cyaneus, Mulder and Cockburn (1993) reported the presence of a prominent tip at the anterior end of the cloacal protuberance and that both the cloacal protuberance and the cloacal tip were 
found in males only during the breeding season. A prominent cloacal tip has not, to our knowledge, been reported in any other avian species. Mulder and Cockburn (1993) suggested that the cloacal tip was cartilaginous and speculated that it may function as an intromittent organ to facilitate sperm transfer. In this study, we show that a cloacal tip is present in several malurid species, describe the structural and histological characteristics of the cloacal tip, and discuss the potential function of the cloacal tip in relation to the varying intensities of sperm competition observed within the Maluridae.

\section{Materials and methods}

\section{Morphology and collection techniques}

We examined males from eight species of Australian Maluridae: splendid $M$. splendens melanotus, superb $M$. cyaneus cyanochlamys, white-winged $M$. leucopterus leuconotus, red-backed $M$. melanocephalus, variegated M. lamberti assimilis and blue-breasted $M$. pulcherrimus fairy-wrens, striated grasswren $A$. striatus striatus, and southern emuwren S. malachurus malachurus. Work was conducted during the austral breeding season over three years (2004-2006), and all individuals used in this study were known to be in breeding condition based on behavioral, morphological or physiological characteristics. We studied populations at seven sites throughout Australia: splendid, white-winged, and variegated fairy-wrens were studied at Brookfield Conservation Park, South Australia; superb fairy-wrens were studied at Murray River National Park, South Australia; striated grasswrens were studied at Pooginook and Cooltong Conservation Parks, South Australia; blue-breasted fairy-wrens were studied at Lincoln National Park, South Australia; red-backed fairy-wrens were studied at Moomin Reservoir and Kalinvale Farm, Atherton Tablelands, Queensland; and southern emuwrens were studied in the Smith's Lake region, New South Wales.

At each site, birds were captured in mist nets, weighed using a Pesola spring balance (to nearest $0.1 \mathrm{~g}$ ), and cloacal protuberance length $(\mathrm{L}$; measured as the distance between the cloacal vent and posterior edge of the protuberance, excluding the cloacal tip), width (W), and depth (D), and the length and width (at base) of the cloacal tip, were measured using digital callipers (to nearest $0.1 \mathrm{~mm}$ ). Cloacal protuberance volume was estimated as volume $=\pi(\mathrm{D} / 2 \times \mathrm{W} / 2) \times \mathrm{L}$ (Tuttle et al. 1996) and we estimated cloacal tip area as area $=0.5$ (tip length $\times$ tip width). We also collected six males of each species (three in the striated grasswren) and removed and preserved the cloacal region (cloacal vent and tip) in 10\% neutral buffered formalin. Testes were removed, length and width measured using digital callipers (to nearest 0.1 $\mathrm{mm}$ ) and fresh weight determined using an electronic balance (Ohaus Navigator, to nearest $0.01 \mathrm{~g}$ ). For each individual, we calculated relative testes size as combined testes mass (left and right testis combined) expressed as a percent of body mass.

\section{Histological techniques}

Following fixation, we removed excess tissue from the cloaca and washed the cloacal tissue with phosphate buffered saline. We dehydrated and cleaned the cloacal tissue via a series of increasing alcohol concentrations $(70 \%$, $80 \%, 95 \%, 100 \%)$, and two changes of xylene, and then passed the tissue through four changes of infiltration paraffin (paraffin type 1, Richard-Allan Scientific) at $60^{\circ} \mathrm{C}$. We then embedded the cloacal tissue in paraffin (paraffin type 9, Richard-Allan Scientific) and cut 5- $\mu \mathrm{m}$ thick sections using a microtome (HM315, Microm). Finally we stained sections with haematoxylin-eosin and trichrome and examined them using polarised light and phase-contrast microscopy.

\section{Statistical analysis}

We investigated the relationship among species mean values using a linear model to ask how tip length was jointly influenced by testes mass (as a proxy for sperm competition intensity) and body mass. We used both the raw species means, and because interspecific comparisons can be confounded by common ancestry, the method of independent contrasts (Felsenstein 1985) implemented in the APE $R$ package (Paradis et al. 2004). Standardised contrasts were calculated for body size (ln transformed), testes size, tip length, width and area, and cloacal protuberance volume. We used an estimate of the phylogenetic relationships of the Maluridae (Christidis and Schodde 1997, Fig. 1) and assumed a punctuated model of evolution (i.e., set all branch lengths equal). The striated grasswren, which was not present on this tree, was replaced with its congener the black grasswren $A$. housei. We regressed the tip contrasts (length, width and area) on the testes and body contrasts, with the regression forced through the origin.

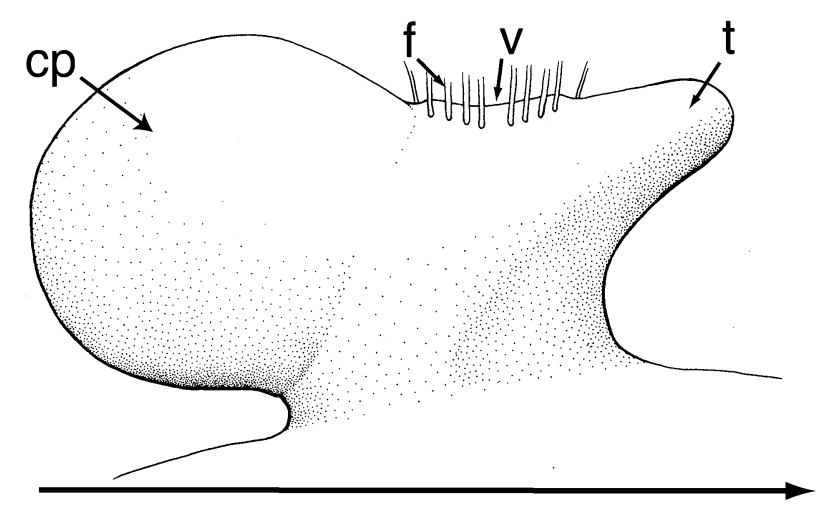

Figure 1. Generalised illustration of the fully developed cloacal protuberance (cp) and cloacal tip (t) of male Maluridae. The cloacal protuberance is a bulbous-type structure, bare except for feathers (f) (truncated in this image) surrounding the cloacal vent (v). The cloacal tip $(\mathrm{t})$ is a prominent projection at the anterior edge of the cloacal protuberance. Illustration shows the lateral view with the bird's head to the right. The arrow indicates the long axis of the cloacal tip. (from photographs by R. Kramer). 


\section{Results}

\section{Gross morphology}

In all fairy-wrens and grasswrens examined, the cloacal protuberance of males was a bulbous-type structure that was mostly bare except for a circle of feathers surrounding the vent (cloacal circlet). In contrast, male southern emu-wrens did not possess a cloacal protuberance. Cloacal protuberances consisted primarily of the paired seminal glomera and varied considerably in size across species (Table 1). In some species, the anterior edge of the cloacal protuberance possessed a prominent cloacal tip (Fig. 1). A cloacal tip was present in male splendid, superb, white-winged, and red-backed fairy-wrens and the striated grasswren. In contrast, the variegated and blue-breasted fairy-wrens and the southern emu-wren lacked an external tip. However, in the variegated and blue-breasted fairy-wrens, but not the emu-wren, histological examination showed that the cloacal region included a small, non-protruding area of structural modification consistent with the tip observed in the other malurid species. Cloacal tips had no feathers or accessory structures and no discernable ducts, external openings or grooves were present on the tip of any species.

In those species with a prominent cloacal tip, mean tip length ranged from 2.38 to $3.39 \mathrm{~mm}$, mean tip width ranged from 1.22 to $2.82 \mathrm{~mm}$, and mean tip area ranged from 1.6 to $4.89 \mathrm{~mm}^{2}$ (Table 1). In all species examined, females did not possess either a cloacal protuberance or a cloacal tip.

\section{Anatomical and histological characterisation}

The following description applies to all species examined that possessed a cloacal tip. The cloacal tip was continuous with, but structurally distinct from, the ventral lip of the cloaca and consisted of two major regions, a superficial dermis/epidermis and a striated muscle layer. The dermis was characterised by variable amounts of connective tissue elements including fibroblasts and associated collagen, elastin, capillaries, and a limited amount of adipose cells. The dermis varied in thickness, being thinner at the apex than at the base of the tip. The epidermis consisted of two layers: 1) an outer flattened cell layer (Stratum corneum) of varying thickness, and 2) a basal cell layer (Stratum germinativum) three to six cells thick. The lateral aspects of the tip possessed both shallow and deep invaginations in which the stratified squamous epithelium gave way to epithelium containing secretary cells. In contrast, the apex of the tip was characterised by a soft keratinised stratified squamous epithelium.

The dominant feature of the cloacal tip was a matrix of striated muscle fibres and connective tissue. A layer of connective tissue (the epimysium), composed predominately of collagen and fibroblasts, surrounded the striated muscle layer and gave rise to connective tissue sheets (the perimysium) that projected into the striated muscle fibres. The perimysium grouped individual muscle fibres into bundles or fascicles. Striated muscle bundles were located bilaterally, separated by a midline septum of connective tissue, and muscle fibres were orientated longitudinally (parallel to the long axis; Fig. 2). Towards the tip's apex, the connective tissue septum was reduced and the bilateral longitudinal muscle fibres formed a region of interdigitation. The striated muscle bundles were not associated with the striated muscle fibres of the cloacal vent. Connective tissue sheets (the perimysium) projecting into the striated muscle bundles were orientated in two anatomical planes, medio-laterally and dorso-ventrally (Fig. 3). Additionally, individual sheets were comprised of a meshwork of connective tissue fibres that exhibited an average fibre angle of $61.3^{\circ}$.

In addition to the lack of association between the musculature of the tip and the musculature of the vent, there was a discernable transition between the striated muscle bundles of the tip and the dominant muscle of the cloacal vent (Muscularis sphincter cloacae) that enveloped the ventral and dorsal cloacae lips and the roof of the proctodeum. The cloacal tip and cloacal vent musculature were further differentiated by differences in the connective

Table 1. Data on body mass, testes mass, cloacal protuberance volume, and cloacal tip dimensions in species of Australian Maluridae. Values reported are means \pm SD and sample size in parentheses.

\begin{tabular}{|c|c|c|c|c|c|c|c|}
\hline Species & $\begin{array}{l}\text { Body mass } \\
(\mathrm{g})\end{array}$ & $\begin{array}{c}\text { Combined } \\
\text { testes mass } \\
(\mathrm{g})\end{array}$ & $\begin{array}{c}\text { Relative testes } \\
\text { size } \\
\text { (Percent of } \\
\text { body mass) }\end{array}$ & $\begin{array}{l}\text { CP volume } \\
\left(\mathrm{mm}^{3}\right)\end{array}$ & $\begin{array}{l}\text { Tip length } \\
\text { (mm) }\end{array}$ & $\begin{array}{l}\text { Tip width } \\
\text { (mm) }\end{array}$ & $\begin{array}{l}\text { Tip area } \\
\left(\mathrm{mm}^{2}\right)\end{array}$ \\
\hline Southern emu-wren & $\begin{array}{c}7.32 \pm 0.28 \\
(6)\end{array}$ & $0.05 \underset{(6)}{ \pm 0} 0.01$ & $\frac{0.62 \pm 0.15}{(6)}$ & $\begin{array}{c}0 \\
(6)\end{array}$ & $\begin{array}{c}0 \\
(6)\end{array}$ & $\begin{array}{c}0 \\
(6)\end{array}$ & $\begin{array}{c}0 \\
(6)\end{array}$ \\
\hline Striated grasswren & $19.23 \pm 0.47$ & $0.34 \pm 0.02$ & $1.78 \pm 0.07$ & $94.11 \pm 16.39$ & $3.39 \pm 0.65$ & $2.82 \pm 0.45$ & $4.89 \pm 1.76$ \\
\hline Variegated fairy-wren & $\begin{array}{c}7.78 \pm 0.78 \\
(5)\end{array}$ & $0.18 \pm 0.03$ & $\begin{array}{c}2.32 \pm 0.33 \\
(5)\end{array}$ & $\begin{array}{c}37.89 \pm 17.18 \\
(36)\end{array}$ & $\begin{array}{c}0 \\
(36)\end{array}$ & $\begin{array}{c}0 \\
(36)\end{array}$ & $\begin{array}{c}0 \\
(36)\end{array}$ \\
\hline Blue-breasted fairy-wren & $8.85 \pm 0.53$ & $0.11 \pm \frac{0.06}{(6)}$ & $1.24 \pm 0.72$ & $28.39 \pm 13.6$ & $\begin{array}{c}0 \\
(15)\end{array}$ & $\begin{array}{c}0 \\
(15)\end{array}$ & $\begin{array}{c}0 \\
(15)\end{array}$ \\
\hline Splendid fairy-wren & $8.4 \pm 0.65$ & $0.29 \pm 0.06$ & $\begin{array}{c}3.43 \pm 0.57 \\
(6)\end{array}$ & $\begin{array}{c}107.10 \pm 38.85 \\
(158)\end{array}$ & $\begin{array}{c}3.06 \pm 0.37 \\
(156)\end{array}$ & $\begin{array}{c}1.76 \pm 0.27 \\
(158)\end{array}$ & $\begin{array}{c}2.72 \pm 0.59 \\
(156)\end{array}$ \\
\hline Superb fairy-wren & $\begin{array}{c}8.93 \pm 0.55 \\
(6)\end{array}$ & $0.29 \pm 0.09$ & $3.27 \pm 1.11$ & $105.03 \pm \frac{ \pm 2}{(6)}$ & $3.16 \pm 0.22$ & $1.59 \pm 0.34$ & $2.53 \pm 0.59$ \\
\hline Red-backed fairy-wren & $\underset{(6)}{7.32 \pm 0.47}$ & $0.21 \pm \frac{0.07}{(6)}$ & $2.95 \pm \frac{1}{(6)}(.05$ & $123.04 \pm 47.74$ & $2.77 \pm 0.37$ & $1.67 \pm 0.07$ & $2.26 \pm 0.13$ \\
\hline White-winged fairy-wren & $\underset{(6)}{7.65 \pm 0.35}$ & $0.33 \underset{(6)}{ \pm 0} 0.05$ & $\underset{(6)}{4.26 \pm 0.51}$ & $\begin{array}{c}86.91 \pm 31.11 \\
(13)\end{array}$ & $\begin{array}{c}2.38 \pm 0.85 \\
(13)\end{array}$ & $\begin{array}{c}1.22 \pm 0.45 \\
(13)\end{array}$ & $\begin{array}{c}1.6 \pm 0.68 \\
(13)\end{array}$ \\
\hline
\end{tabular}




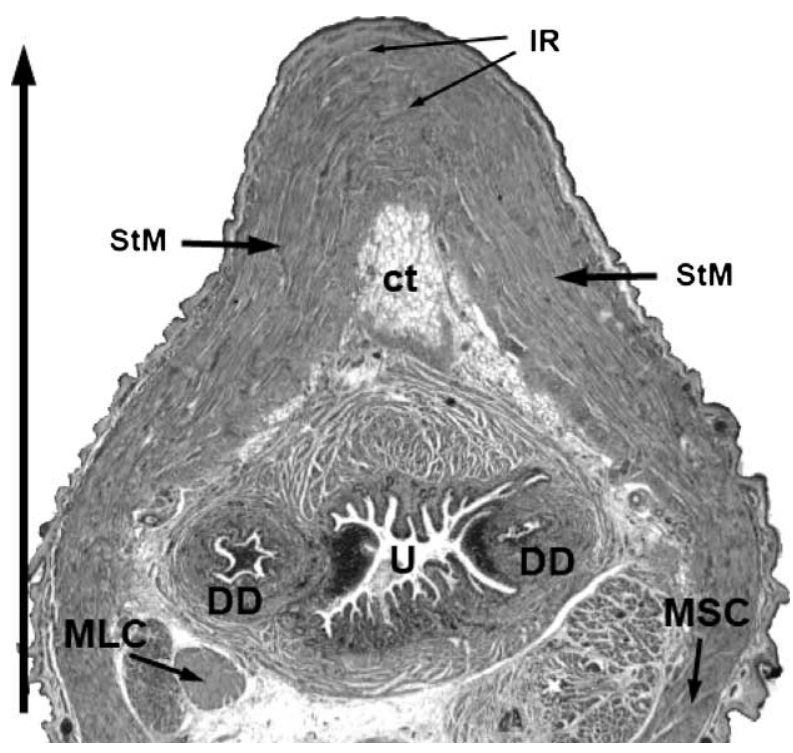

Figure 2. Longitudinal section of the cloacal tip of the splendid fairy-wren showing the bundles of striated muscle (StM) arranged bilaterally with an inter-digitating region (IR) at the apex. The striated muscle fibres are orientated longitudinally (parallel to the long axis) and are separated by a midline septum of connective tissue (ct). Near the base of the cloacal tip the thicker striated muscle bundles (StM) transition to the more attenuated cloacal musculature Muscularis sphincter cloacae (MSC), where the dense connective tissue enveloping the striated muscle bundles is nearly absent. Medial to the cloacal musculature is a transverse view of the Muscularis levator cloacale (MLC), the urodeum (U), and the ductus deferens (DD). The luminal mucosa of the urodeum is extensively pleated. The arrow on the left indicates the long axis of the cloacal tip.

tissue septa, which was considerably less voluminous in the cloacal vent region.

As in other avian species, paired papillae were present in the urodeum of the cloaca. The papillae were wart-like projections of the ductus deferens, representing the exit point for sperm, and were surrounded by a fibro-muscular sheath of smooth muscle. Both the urodeum and ductus deferens consisted of cuboidal-columnar epithelium cells and the lamina propria of the ductus deferens was densely populated with capillaries. There was, however, no evidence of a lymph vessel complex or a vascular body (Corpus paracloacalis vascularis).

\section{Species comparisons}

Mean testes mass ranged from 0.05 to $0.34 \mathrm{~g}$, or 0.62 to $4.26 \%$ of male body mass (Table 1). Across species, mean cloacal tip length was positively correlated with mean combined testes mass $(\mathrm{r}=0.87, \mathrm{n}=8, \mathrm{P}=0.005)$ and moderately, but not significantly, correlated with mean body mass $(\mathrm{r}=0.42, \mathrm{n}=8, \mathrm{P}=0.29)$. In a model that included both testes mass and body mass, cloacal tip length was positively related to testes mass (raw species data: $\mathrm{t}_{5}=3.37, \mathrm{P}=0.01$; independent contrasts: $\mathrm{t}_{5}=3.22$, $\mathrm{P}=0.023$; Fig. 4), but not body mass (raw species data: $t_{5}=0.06, P=0.96$; independent contrasts: $t_{5}=-0.38$, $\mathrm{P}=0.72$ ). Similar $\mathrm{P}$ values were obtained for analyses using mean tip width and area instead of mean tip length.

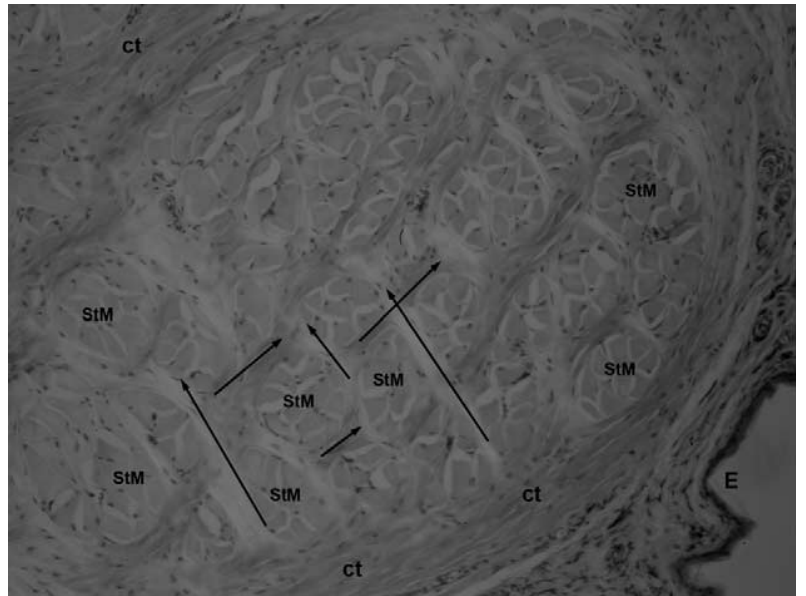

Figure 3. Cross section of the cloacal tip of the red-backed fairywren viewed with polarised light microscopy showing the twodimensional matrix of connective tissue. Bundles of striated muscle fibres (StM) are surrounded by connective tissue sheets (perimysium) orientated medio-laterally and dorso-ventrally (illustrated by arrows). Larger sheets (epimysium) of connective tissue (ct) surround the entire striated muscle bundles. Also in view the epidermis (E).

\section{Discussion}

Although the myological origin of the cloacal tip in Maluridae remains unclear, the tip was structurally distinct from the musculature of the cloacal vent. The tip was comprised of connective tissue and striated muscle bundles and showed no evidence of fibrous bodies, vascular bodies, vascularisation or lymphatic tissue. This suggests that the cloacal tip in Maluridae is best categorised as a non-erectile muscular appendage or phallus-like structure of the cloacal protuberance.

A phallus is observed in only $3 \%$ of bird species (Briskie and Montgomerie 1997, Briskie and Montgomerie 2001). There are two main anatomical varieties of phallus: 1) a non-intromittent phallus, which deposits sperm onto the female's external genitalia, in some galliforms such as the domestic fowl Gallus and turkey Meleagris, and 2) a true intromittent phallus, which is inserted directly into the female's cloaca (King 1981). Intromittent phalli can be subdivided into two forms: a) an intromittent phallus with a tubular cavity, observed in the rhea Rhea, emu Dromaius, and in cassowaries Casuarius spp., waterfowl Anatidae and screamers Anhimidae (King 1981, Briskie 1998, Coker et al. 2002), and b) an intromittent phallus lacking a cavity, observed in kiwi Apteryx spp., tinamous Tinamidae and the ostrich Strutho camelus (King 1981). In all forms of phallus, the mechanism of erection appears to be lymphatic engorgement (King 1981, Knight et al. 1984, Gee et al. 2004), and all phalli are characterised by the presence of a median groove or phallic sulcus (groove) along which sperm is transported during insemination (King 1981, Coker et al. 2002, Gee et al. 2004).

Phallus-like structures also occur in the greater vasa parrot Coracopsis vasa, the buffalo-weaver Bubalornis spp., and some members of Cracidae Crax and Penelope (King 1981, Bentz 1983, Wilkinson and Birkhead 1995). In the 


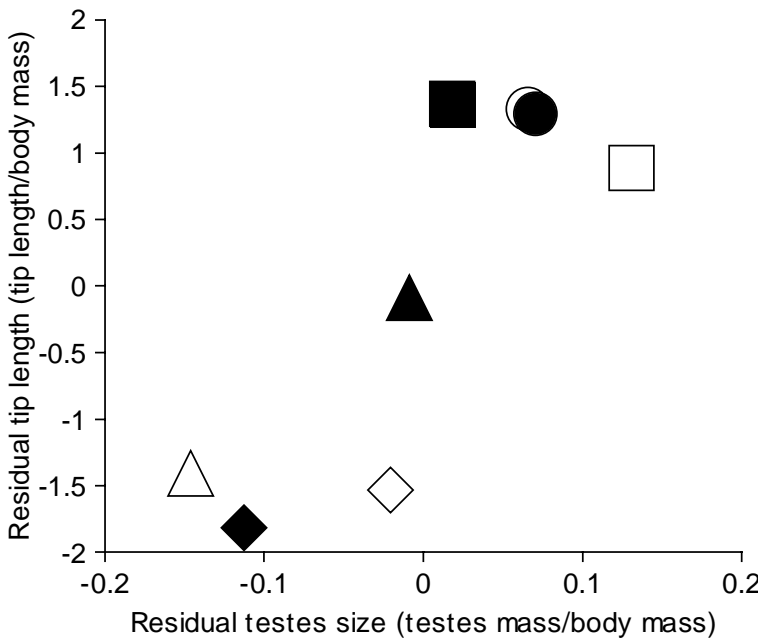

Figure 4. Relationship between residual cloacal tip length (cloacal tip length/body mass) and residual testes size (testes mass/body mass) across species of Australian Maluridae (species data: $\mathrm{R}^{2}=$ $0.72, \mathrm{P}=0.02$; independent contrasts: $\left.\mathrm{R}^{2}=0.67, \mathrm{P}=0.03\right)$. blue-breasted fairy; red-backed fairy-wren; splendid fairywren; $\bigcirc$ superb fairy-wren; $\diamond$ variegated fairy-wren; $\square$ whitewinged fairy-wren; $\boldsymbol{\Delta}$ striated grasswren; $\Delta$ southern emu-wren.

buffalo-weaver, the phalloid organ is a prominent structure projecting from the external surface of the ventral wall of the cloaca, just cranial to the ventral cloacal lip, resulting from the seasonal hypertrophy of the cloacal musculature. The organ is non-erectile and is comprised of connective tissue (Bentz 1983, Winterbottom et al. 2001). In this respect, the cloacal tip in the Maluridae is most analogous to the phalloid organ of the buffalo-weaver. However, the cloacal tip of malurids also consists of striated muscle fibres that extend to the apex of the structure. Consequently, the cloacal tip of Maluridae represents a unique morphological feature of male avian reproductive anatomy and almost certainly evolved independently of the buffalo-weaver phallus.

Two key structural details of the cloacal tip provide information that allows us to infer its function. First, keratinisation of epithelium is well suited to areas experiencing constant contact and abrasion, which causes cells to slough off and be rapidly replaced by the basal cell layer. Furthermore, keratin protects and maintains hydration of tissue. Second, the longitudinal orientation of muscle fibres within a two-dimensional matrix of connective tissue indicates that the cloacal tip is a muscular hydrostat, similar in structure to the tongues of mammals and lizards, the trunk of the elephant, and the appendages of cephalopods (Smith and Kier 1989, Johnsen and Kier 1993). A muscular hydrostat is a structure composed almost entirely of muscle fibres arranged in a three-dimensional array (Kier and Smith 1985, Smith and Kier 1989), and is capable of diverse and highly controlled movements without skeletal support because muscles act as both the effector of movement and as the support for movement (Kier 1992). In a hydrostat, connective tissue may also fill the role of antagonistic muscle because connective tissue fibres can store elastic energy, providing an 'elastic recoil' system that forces the contracted muscles to elongate (Gosline et al. 1983). In the cloacal tip of the Maluridae, the arrangement of muscle fibres in a single anatomical plane (longitudinal) suggest a single plane of movement, with the connective tissue providing the recoil to cause contracted muscle to elongate rather than movement in additional planes. More specifically, contraction of the bilaterally located longitudinal muscle bundles in the cloacal tip would likely result in movement in the medio-lateral plane, with support and recoil provided by the two-dimensional matrix of connective tissue.

We consider four possible functional hypotheses for the cloacal tip: 1) display, 2) structural counterbalance, 3) female choice for large cloacal protuberance, and 4) facilitation of sperm transfer. We do not necessarily consider this list exhaustive, nor the hypotheses necessarily mutually exclusive, and until comprehensive observations of cloacal contact in these species are achieved we cannot entirely rule out any of these different hypotheses. Despite these limitations, however, knowledge of the structure of the cloacal tip allows us to provide some support for or against each of these hypotheses and here we consider each in turn.

The display hypothesis proposes that the cloacal tip functions in male pre-copulatory displays to attract future copulations. In fairy-wrens, a number of courtship displays have been described including modified flight patterns, plumage displays, and petal carrying (Mulder 1997, Rowley and Russell 1997). However, there is not a single description or indication of males presenting or displaying their cloaca to females during pre-copulatory display, suggesting the display hypothesis is unlikely to explain the cloacal tip of male malurids.

The structural counterbalance hypothesis proposes that the cloacal tip functions simply to counterbalance the mass of the cloacal protuberance. This is unlikely as a structural counterbalance would only be effective in a horizontal plane whereas the cloacal protuberance-cloacal tip is positioned in the dorso-ventral plane. Second, muscle tissue is expensive to produce and maintain relative to connective tissue (due to the higher density of cellular elements in muscle), thus the specialised muscular arrangement of the tip would not seem to be a cost-effective counterbalance. Finally, the lack of an obvious cloacal tip in variegated and blue-breasted fairy-wrens, species with a conspicuous cloacal protuberance, suggests a counterbalance is not required or is only necessary once the mass of the seminal glomera exceeds some threshold.

The female choice hypothesis proposes that the cloacal tip increases the overall size of a male's cloacal protuberance. Generally, both within and across species, the size of the cloacal protuberance reflects the number of stored sperm (Birkhead et al. 1993, Tuttle et al. 1996, Rowe and Pruett-Jones 2006, but see Birkhead and Hoi 1994 for an exception). By copulating with males with large protuberances, females may gain direct benefits in terms of fertility assurance and/or indirect benefits through sons inheriting a large protuberance. Under the assumption that females are able to assess protuberance size via contact during copulation, and prefer large protuberances, cloacal tips may be favoured because they increase the apparent size of the protuberance. However, the complex arrangement of muscle fibres and connective tissue seem both unnecessary and cost inefficient as a means to increase cloacal protuberance size. 
The facilitation of sperm transfer hypothesis could operative through several ways, including a true intromittent organ, mechanical manipulation of the female cloaca, and female stimulation via a stimulatory organ. Mulder and Cockburn (1993) speculated that the cloacal tip might function as an intromittent organ. Unfortunately, copulation is rarely observed in fairy-wrens (Mulder and Cockburn 1993, Webster et al. 2004) and we have not been able to observe copulation closely enough to determine if the cloacal tip is a truly intromittent structure that facilitates sperm transfer. However, the tip is not homologous to the intromittent organs of other birds. The tip is not associated with the dorsal proctodeal wall or the paired papillae of the cloacae and does not bear a phallic sulcus or groove or possess an internal duct for sperm transfer. Additionally, the tip lacks the extensive lymph vessel complex or a vascular body involved in the formation of a lymph-like fluid responsible for erection in avian phalli (Knight et al. 1984). Furthermore, the structure of the cloacal tip implies movement in the medio-lateral plane, thus it seems unlikely that the tip would be able to articulate to the appropriate angle to enter the female's cloaca. Consequently, we find little support for a true intromittent organ as a mechanism to facilitate sperm transfer.

Alternatively, the cloacal tip could function to facilitate sperm transfer by mechanically manipulating the female cloaca, pushing the dorsal cloacal lip upwards and causing eversion of the cloacal chamber. In most birds (i.e., those without a phallus), a successful copulation involves the transfer of sperm through brief cloacal contact (cloacal kissing). Greater cloacal eversion should provide sperm with access to a deeper portion of the vagina and may therefore increase the number of the male's sperm taken into the female reproductive tract. This mechanism seems plausible based on the kind of contact expected between males and females during copulation. The expected alignment of the male and female cloacae would lead to a site of contact between the cloacal tip of males and the region between and including the dorsal cloacal lip and the tail of the female. This structural evidence is suggestive of a mechanical function of the cloacal tip in facilitating sperm transfer. The muscular arrangement of the tip, however, infers movement in a medio-lateral plane only, whereas shortening and elongation would seem more suitable to mechanical distention of the female cloaca.

Lastly, the cloacal tip may facilitate sperm transfer by stimulating the female. Females may be influenced to: a) eject previously deposited sperm, b) bias sperm use via preferential transport, uptake and/or storage of sperm within the reproductive tract, or c) evert the cloacal chamber to allow sperm increased accessibility to the vaginal lumen and permit deeper transfer of sperm. The alignment of the male and female cloacae during copulation is such that the cloacal tip would contact the region between and including the dorsal cloacal lip and the tail of the female. This may be a site of stimulation, and if so the cloacal tip may stimulate the female to increase the eversion of her cloaca during copulation, resulting in greater sperm uptake. Cloacal eversion has been shown to be important in artificial insemination techniques in poultry. During artificial insemination in poultry, the region above the cloaca (between the cloaca and the tail) is manually stimulated through massage and pressure, resulting in eversion of the vagina (Bakst and Bahr 1993). This technique is undertaken to allow the insemination to access a deeper portion of the female reproductive tract. Deep vaginal inseminations have been shown to result in the highest fertility in turkey hens (Wentworth et al. 1975), supporting the idea that more of the male's sperm are taken up and/or retained in the female reproductive tract as a result of cloacal eversion.

In birds, paternity success follows a 'raffle principle' in which the success of each male is proportional to the relative numbers of their sperm in the female reproductive tract at the time of fertilisation (Parker 1990a,b). Typically it is the last insemination a female receives that fertilises the majority of subsequent offspring, a phenomenon referred to as last male sperm precedence. Last male precedence is thought to occur primarily because of passive sperm loss, whereby sperm passively leak from storage sites in the female reproductive tract (Birkhead 1998a,b, Birkhead and Biggins 1998). Consequently, the last male to inseminate a females will have a numerical advantage in terms of sperm numbers and subsequent fertilisation success, simply because at the time of fertilisation less of the last male's sperm has been lost (Birkhead 1998a). Across malurid species, cloacal tip length was positively related to testes mass, independent of body size and phylogenetic relationships. Therefore, species inferred to experience more intense sperm competition exhibit a longer cloacal tip. This suggests the cloacal tip may have evolved in response to sperm competition as a trait conferring a fertilisation advantage to males. Specifically, the unique cloacal tip of male malurid species may function to increase a male's likelihood of paternity success by increasing the relative number of his sperm in the female reproductive tract at the time of fertilisation. If we are correct that the cloacal tip functions to stimulate females during copulation, the cloacal tip may represent a unique male adaptation to sperm competition.

Acknowledgements - We are grateful for the assistance, advice, and support from Valorie Akuffo, Toby Bolton, Bob Delaine, Win Filewood, Jody Gates, Emma Greig, Philippa Horton, Xin Jiang, Jordan Karubian, Emily Kay, Rebecca Kramer, Mike LaBarbera, Terry Li, Willow Lindsay, Anthony Montag, Ally Phillimore, Trevor Price, Christina Rockwell, Wen Shen, Alex Smith, Claire Varian, Michael Webster, Peter Wilkins, and Veronica Yoyovich. This paper was improved by comments received by Trevor Price, Jill Mateo, James Briskie and two anonymous reviewers. All work was undertaken with approval from the University of Chicago Animal Care and Use Committee and appropriate Australian state permits. This work was supported by the National Science Foundation (SP-J) and the Hinds Fund from the University of Chicago (MR).

\section{References}

Bakst, M. R. and Bahr, J. 1993. Poultry. - In: Hafez, E. S. E. (ed.), Reproduction in farm animals. Lea and Febiger, Philadelphia, pp. 385-402.

Bentz, G. D. 1983. Myology and histology of the phalloid organ of the buffalo weaver (Bubalornis albirostris). - Auk 100: 501504.

Birkhead, T. R. 1998a. Sperm competition in birds. - Rev. Reprod. 3: 123-129. 
Birkhead, T. R. 1998b. Sperm competition in birds: mechanisms and function. - In: Birkhead, T. R. and Møller, A. P. (eds), Sperm competition and sexual selection. Academic Press, London, pp. 579-622.

Birkhead, T. R. and Biggins, J. D. 1998. Sperm competition mechanisms in birds: models and data. - Behav. Ecol. 9: 253260.

Birkhead, T. R. and Hoi, H. 1994. Reproductive organs and mating strategies of the bearded tit Panurus biarmicus. - Ibis 136: 356-360.

Birkhead, T. R. and Møller, A. P. 1992. Sperm competition in birds: evolutionary causes and consequences. - Academic Press, London.

Birkhead, T. R., Briskie, J. V. and Møller, A. P. 1993. Male sperm reserves and copulation frequency in birds. - Behav. Ecol. Sociobiol. 32: 85-93.

Briskie, J. V. 1998. Avian genitalia. - Auk 115: 826-828.

Briskie, J. V. and Montgomerie, R. 1997. Sexual selection and the intromittent organ of birds. - J. Avian Biol. 28: 73-86.

Briskie, J. V. and Montgomerie, R. 2001. Efficient copulation and the evolutionary loss of the avian intromittent organ. - J. Avian Biol. 32: 184-187.

Christidis, L. and Schodde, R. 1997. Relationships within the Australo-Papuan fairy-wrens (Aves: Malurinae): an evaluation of the utility of allozyme data. - Aust. J. Zool. 45: 113-129.

Coker, C. R., McKinney, F., Hays, H., Briggs, S. V. and Cheng, K. M. 2002. Intromittent organ morphology and testis size in relation to mating system in waterfowl. - Auk 119: 403-413.

Dunn, P. O., Whittingham, L. A. and Pitcher, T. E. 2001. Mating systems, sperm competition, and the evolution of sexual dimorphism in birds. - Evolution 55: 161-175.

Felsenstein, J. 1985. Phylogenies and the comparative method. - Am. Nat. 125: 1-15.

Gee, G. F., Bertschinger, H., Donoghue, A. M., Blanco, J. and Soley, J. 2004. Reproduction in nondomestic birds: physiology, semen collection, artificial insemination and cryopreservation. - Avian and Poult. Biol. Rev. 15: 47-101.

Gosline, J. M., Steeves, J. D., Harman, A. D. and Demont, M. E. 1983. Patterns of circular and radial mantle muscle activity in respiration and jetting of the squid Loligo opalescens. - J. Exp. Biol. 104: 97-109.

Johnsen, S. and Kier, W. M. 1993. Intramuscular crossed connective tissue fibres: skeletal support in the lateral fins of squid and cuttlefish (Mollusca: Cephalopoda). - J. Zool. 231: 311-338.

Karubian, J. 2002. Costs and benefits of variable breeding plumage in the red-backed fairy-wren. - Evolution 56: 1673-1682.

Kier, W. M. 1992. Hydrostatic skeletons and muscular hydrostats. - In: Biewener, A. A. (ed.), Biomechanics (structures and systems): a practical approach. Oxford University Press, New York, pp. 205-231.

Kier, W. M. and Smith, K. K. 1985. Tongues, tentacles and trunks: the biomechanics of movement in muscular-hydrostats. - Zool. J. Linn. Soc. 83: 307-324.

King, A. S. 1981. Phallus. - In: King, A. S. and McLelland, J. (eds.), Form and function in birds, vol 2. Academic Press, London, pp. 107-147.

Knight, C. E., Bakst, M. R. and Cecil, H. C. 1984. Anatomy of the Corpus vasculare paracloacale of the male turkey. - Poult. Sci. 63: 1883-1891.

Maguire, G. S. and Mulder, R.A. 2004. Breeding biology and demography of the southern emu-wren (Stipiturus malachurus). - Aust. J. Zool. 52: 583-604.

Møller, A. P. 1988. Female choice selects for male sexual tail ornaments in the monogamous swallow. - Nature 332: 640 642.
Møller, A. P. 1991. Sperm competition, sperm depletion, paternal care, and relative testis size in birds. - Am. Nat. 137: 882-906.

Møller, A. P. and Briskie, J. V. 1995. Extra-pair paternity, sperm competition and the evolution of testis size in birds. - Behav. Ecol. Sociobiol. 36: 357-365.

Mulder, R. A. 1997. Extra-group courtship displays and other reproductive tactics of superb fairy-wrens. - Aust. J. Zool. 45: 131-143.

Mulder, R. A. and Cockburn, A. 1993. Sperm competition and the reproductive anatomy of male superb fairy-wrens. - Auk 110: 588-593.

Mulder, R. A., Dunn, P. O., Cockburn, A., Lazenby-Cohen, K. A. and Howell, M. J. 1994. Helpers liberate female fairy-wrens from constraints on extra-pair mate choice. - Proc. R. Soc. B 255: 223-229.

Nakamura, M. 1990. Cloacal protuberance and copulation behavior of the alpine accentor (Prunella collaris). - Auk 107: 284-295.

Nicholls, E. H., Burke, T. and Birkhead, T. R. 2001. Ejaculate allocation by male sand martins, Riparia riparia. - Proc. R. Soc. B 268: 1265-1270.

Paradis, E., Claude, J. and Strimmer, K. 2004. APE: analysis of phylogenetics and evolution in $\mathrm{R}$ language. - Bioinformatics 20: 289-290.

Parker, G. A. 1970. Sperm competition and its evolutionary consequences in the insects. - Biol. Rev. 45: 525-567.

Parker, G. A. 1990a. Sperm competition games: raffles and roles. - Proc. R. Soc. B 242: 120-126.

Parker, G. A. 1990b. Sperm competition: sneaks and extra-pair copulations. - Proc. R. Soc. B 242: 127-133.

Pitcher, T. E., Dunn, P. O. and Whittingham, L. A. 2005. Sperm competition and the evolution of testes size in birds. - J. Evol. Biol. 18: 557-567.

Rowe, M. and Pruett-Jones, S. 2006. Reproductive biology and sperm competition in Australian fairy-wrens. - Avian and Poult. Biol. Rev. 17: 21-37.

Rowley, I. and Russell, E. 1997. Fairy-wrens and Grasswrens: Maluridae. - Oxford University Press, Oxford.

Smith, K. K. and Kier, W. M. 1989. Trunks, tongues, and tentacles: moving with skeletons of muscle. - Am. Sci. 77: 2935.

Tuttle, E. M., Pruett-Jones, S. and Webster, M. S. 1996. Cloacal protuberances and extreme sperm production in Australian fairy-wrens. - Proc. R. Soc. B 263: 1359-1364.

Tuttle, E. M. and Pruett-Jones, S. 2004. Estimates of extreme sperm production: morphological and experimental evidence from reproductively promiscuous fairy-wrens (Malurus). - Anim. Behav. 68: 541-550.

Webster, M. S., Tarvin, K. A., Tuttle, E. M. and Pruett-Jones, S. 2004. Reproductive promiscuity in the splendid fairy-wren: effects of group size and auxiliary reproduction. - Behav. Ecol. 15: 907-915.

Webster, M. S., Tarvin, K. A., Tuttle, E. M. and Pruett-Jones, S. 2007. Promiscuity drives sexual selection in a socially monogamous bird. - Evolution 61: 2205-2211.

Wentworth, B. C., Wineland, M. J. and Paton, G. D. 1975. Fertility of turkey hens correlated with depth of insemination. - Poult. Sci. 54: 682-687.

Wilkinson, R. and Birkhead, T. R. 1995. Copulation behaviour in the vasa parrots Coracopsis vasa and C. nigra. - Ibis 137: 117119.

Winterbottom, M., Burke, T. and Birkhead, T. R. 2001. The phalloid organ, orgasm and sperm competition in a polygynandrous bird: the red-billed buffalo weaver (Bubalornis niger). - Behav. Ecol. Sociobiol. 50: 474-482. 